\title{
Representações sociais acerca do HIV/AIDS e a gestão de riscos em tempos de cronificação da doença
}

\author{
Social representations about HIV/AIDS and management of the risks in time of chronical disease
}

Representaciones sociales sobre el VIH-SIDA y la gestión de riesgos en tiempos de enfermedad

crónica

Recebido: 17/07/2021 | Revisado: 26/07/2021 | Aceito: 05/08/2021 | Publicado: 09/08/2021

\author{
Helena Eri Shimizu \\ ORCID: https://orcid.org/0000-0001-5612-5695 \\ Universidade de Brasília, Brasil \\ E-mail: shimizu@unb.br
}

\begin{abstract}
Resumo
Objetivos: Conhecer as representações sociais acerca do HIV/AIDS, bem como o manejo da gestão de risco no contexto da cronificação da doença. Métodos: Estudo qualitativo fundamentado na Teoria das Representações Sociais. Foram realizadas sete entrevistas com pessoas que se auto-referiram Lésbicas, Gays, Bissexuais e Transgêneros, residentes no Distrito Federal, no período de setembro de 2018 a setembro de 2019, as quais foram analisadas no software Iramuteq: Classificação Hierárquica Descendente e Analise de Similitude. Resultados: Obtiveram-se três eixos temáticos: o primeiro eixo composto pela classe cinco mostrou que todos estão expostos a diversos tipos de riscos. O segundo eixo demonstrou o enfrentamento do estigma e dificuldades para gerir os riscos no contexto da cronificação da doença, constituído pelas classes três que abordou a exclusão social e a violência, e a classe dois mostrou as dificuldades e os limites da gestão do risco. O terceiro eixo compostos pelas classes quatro e classe um retrataram a dolorosa experiência de submissão as violências e a possiblidade da morte pelo HIV/AIDS. A negociação das medidas de prevenção das Infecções Sexualmente Transmissíveis constitui-se a principal barreira, aliadas ao estigma e exclusão. Conclusões: Há que se continuar investindo em estratégias inovadoras, que reforcem a importância do autocuidado da sexualidade responsável, integradas e inter-relacionadas às diferentes etapas do curso da vida.
\end{abstract}

Palavras-chave: HIV; Síndrome de imunodeficiência adquirida; Prevenção de doenças.

\begin{abstract}
The aim of the study is to know the social representations about HIV-AIDS, as well as the management of risk management in the context of the disease's chronicity. Method qualitative based on the Theory of Social Representations. Seven life story interviews were conducted with people who self-reported Lesbians, Gays, Bisexuals and Transgender, residents of the Federal District, in the period from September 2018 to September 2019, which were analyzed with the Iramuteq software: Descending Hierarchical Classification and Similitude Analysis. Results: Three thematic axes were obtained: the first axis composed of class five showed that everyone is exposed to different types of risks. The second axis demonstrated the confrontation of stigma and difficulties in managing risks in the context of the chronicity of the disease, constituted by the classes three that addressed social exclusion and violence, and class two showed the difficulties and limits of risk management. The third axis composed of classes four and class one portrayed the painful experience of submission to violence and the possibility of death from HIV/AIDS. The negotiation of measures to prevent Sexually Transmitted Infections is the main barrier, together with stigma and exclusion. Conclusions: It is necessary to continue investing in innovative strategies that reinforce the importance of self-care for responsible sexuality, integrated and interrelated to the different stages of the trajectory of life.
\end{abstract}

Keywords: HIV; Acquired immunodeficiency syndrome; Disease prevention.

\section{Resumen}

Objetivos: Conocer las representaciones sociales sobre VIH-SIDA, así como la gestión de la gestión de riesgos en el contexto de la cronicidad de la enfermedad. Método cualitativo basado en la Teoría de las Representaciones Sociales. Se realizaron siete entrevistas de historias de vida con personas que se reportaron como Lesbianas, Gays, Bisexuales y Transgénero, residentes en el Distrito Federal, en el período de septiembre de 2018 a septiembre de 2019, las cuales fueron analizadas con el software Iramuteq: Clasificación Jerárquica Descendente y Análisis de Similitudes. Resultados: Se obtuvieron tres ejes temáticos: el primer eje compuesto por la clase cinco mostró que todas las personas están expuestas a diferentes tipos de riesgos, tres que abordaron la exclusión social y la violencia, y la clase dos mostró las dificultades y límites de la gestión del riesgo. El segundo eje demostró el enfrentamiento del estigma y 
las dificultades en la gestión de riesgos en el contexto de la cronicidad de la enfermedad, compuesto por las clases tres que abordaron la exclusión social y la violencia, y la clase dos mostró las dificultades y límites de la gestión de riesgos. El tercer eje compuesto por las clases cuatro y la clase uno retrataba la dolorosa experiencia del sometimiento a la violencia y la posibilidad de muerte por VIH/SIDA. La negociación de medidas para prevenir las infecciones de transmisión sexual es la principal barrera, junto con el estigma y la exclusión. Conclusiones: Es necesario seguir invirtiendo en estrategias innovadoras que refuercen la importancia del autocuidado para la sexualidad responsable, integrada e interrelacionada con las diferentes etapas del curso de la vida.

Palavras clave: HIV; Síndrome de inmunodeficiencia adquirida; Prevención de enfermidade.

\section{Introdução}

A epidemia de HIV/aids, com a qual convivemos há quase quatro décadas, permanece como um grave problema de saúde pública/saúde coletiva, tanto em termos de prevenção como de assistência (United Nations, 2016; World Health Organization, 2000). No contexto atual, apesar da ampliação da oferta de exames para conhecimento da situação sorológica e os esforços de universalização da medicação antirretroviral, continua alto o número de pessoas vivendo com HIV/aids (Ministério da Saúde, 2020; World Health Organization, 2000).

No Brasil, em 2019, foram diagnosticados 41.909 novos casos de HIV e 37.308 casos de aids, com uma taxa de detecção de 17,8/100 mil habitantes (Pereira et al., 2018). Segundo os critérios da Organização Mundial da Saúde (OMS), no Brasil, a epidemia do HIV/aids configura-se como concentrada (World Health Organization, 2000), sobretudo nas populaçõeschave: Usuários de Drogas Injetáveis, homens que fazem sexo com homens e mulheres profissionais do sexo (Kerr et al., 2013; Pereira et al, 2018).

A prevenção constitui-se um grande desafio da prevenção do HIV/aids, todavia são inúmeras as dificuldades, sobretudo devido a manutenção de preconceitos e dos embates morais que envolvem a doença, principalmente por ser de transmissão sexual (Cunha, 2018; Kerr, et al., 2018; Simões, 2018), que são agravadas pelas fragilidades das ações programáticas (Calazans, 2018).

Não há duvidas de que, nos últimos anos, houve investimentos para que a população conheça a doença e as suas formas de transmissão, considerados estratégicos para a gestão de risco (Cunha, 2018). A gestão (ou gerenciamento) de risco é usualmente compreendida como um processamento cognitivo, no qual avaliações são realizadas pela pessoa para decidir sobre a escolha que tomará de se prevenir ou não, em função do conhecimento sobre o agravo e os modos de prevenção (Rios et al., 2019).

A cronificação da aids (anos 2010), ao mesmo tempo que trouxe maior esperança no futuro, contribuiu para menor importância atribuída à noção de morte, conformando novas formas de pensar e de agir (Cecilio et al., 2020; Hipólito et al., 2020; França et al., 2020), além de imprimir, principalmente, mudanças na percepção do tempo para a cena das preocupações imediatas, o que certamente tornou a gestão do risco mais complexa.

Portanto, há que se continuar investindo em práticas de prevenção para garantir o direito à proteção, que tem demonstrado ser o meio mais eficiente e eficaz para reduzir a exposição, adoecimento e mortes por HIV/aids. Ademais, várias pesquisas mostraram que os contextos e as emoções são, muitas vezes, mais importantes para a exposição ao HIV do que o conhecimento, normalmente agravadas pelo estigma e preconceito (Rios et al., 2019), assim, justifica-se a importância de compreender o processo de construção das representações sociais do HIV/aids, que envolve aspectos cognitivos e afetivos (Jodelet, 2001), e poderá ajudar nas práticas de prevenção que envolvam a gestão do risco, para além dos aspectos biológicos.

Este estudo teve como objetivo conhecer as representações sociais acerca do HIV/aids, bem como o manejo da gestão de risco no contexto da cronificação da doença. 


\section{Metodologia}

Trata-se de estudo qualitativo fundamentado na Teoria das Representações Sociais.

Utilizou-se a técnica bola de neve para recrutar os participantes do estudo. Sete pessoas que se auto referiram LGBT (Lesbica, Gays, Bissexual e Transgênero), maiores de 18 anos, moradoras do Distrito Federal, consentiram a realização das entrevistas e assinaram o Termo de Consentimento Livre e Esclarecido. Para preservar o anonimato foram utilizados códigos para cada um das entrevistas (Ent1 a Ent7). A coleta de dados ocorreu no período de setembro de 2018 a setembro de 2019 . O projeto multicêntrico foi aprovado pelo Comitê de Ética em pesquisa (CAAE43133915.9.0000.5054 sob o número 1.024.053).

Realizaram-se entrevistas em profundidade, na modalidade de história de vida, que foram transcritas e analisadas no software Interface de R pour les Analyses Multidimensionnelles de Textes et de Questionnaires (Iramuteq), que classifica a ocorrência das palavras para o interior de um corpus (Reinert,1990). Para organizar e classificar os discursos, esse software segmenta o texto, e a seguir estabelece as semelhanças entre os segmentos e hierarquias de classes de palavras por meio de arranjos de sentido (Camargo \& Justo, 2013, 2015). Em realidade, o software auxilia na análise de conteúdo, mais especificamente, na modalidade de coocorrência, permitindo obter classes de segmentos de texto que, ao mesmo tempo, apresentam vocabulário semelhante entre si, e vocabulário diferente dos segmentos de texto das outras classes (Camargo \&, Justo, 2013, 2015).

$\mathrm{Na}$ primeira etapa do estudo, o corpus que continha sete entrevistas foi submetido à Classificação Hierárquica Descendente (CHD), que agrupa os segmentos de texto em função dos seus respectivos vocabulários, e o conjunto deles é dividido com base na frequência das formas reduzidas (palavras já lematizadas). Esta análise visa obter classes que, ao mesmo tempo, apresentam palavras análogas entre si, e palavras diferentes das outras classes (Camargo \& Justo, 2013, 2015).

Na segunda etapa, o corpus foi submetido a Analise de Similitude, que se baseia na teoria dos grafos, possibilita identificar as coocorrências entre as palavras e seu resultado traz indicações da conexidade entre as palavras, auxiliando na identificação da estrutura de um corpus textual, caracterizando também as partes comuns e as especificidades em função das variáveis descritivas identificadas na análise (Camargo, Justo, 2013, 2015; Silva \& Emuno, 2017).

\section{Resultados}

Do corpu oriundos das sete entrevistas, foram analisados 971 segmentos de texto (ST), retendo-se 89,1\% do total, que deu origem a um dendograma (Figura 1) composto por cinco classes subdivididas em três eixos temáticos: o primeiro eixo composto pela classe cinco (12,3\%), mostrou que todos estão expostos a diversos tipos de riscos O segundo eixo demonstrou o enfrentamento do estigma e as dificuldades para gerir os riscos no contexto da cronificação da doença, constituído pelas classes três $(14 \%)$ que abordou a exclusão social e a violência, e a classe dois (26,8\%) que mostrou as dificuldades e os limites da gestão do risco. O terceiro eixo compostos pelas classes quatro $(11,1 \%)$ e classe um $(35,9 \%)$ retrataram a dolorosa experiência de conviver com pessoas que tiveram HIV/Aids e morreram devido a doença. 
Figura 1 - Representações Sociais do HIV-aids e gestão de risco em tempos de cronificação da doença.

\begin{tabular}{|c|c|c|c|c|c|c|c|c|c|}
\hline \multicolumn{2}{|c|}{$\begin{array}{l}\text { Primeiro Eixo: Todos } \\
\text { estão expostos a diversos } \\
\text { tipos de riscos. }\end{array}$} & \multicolumn{4}{|c|}{$\begin{array}{l}\text { Segundo eixo: Enfrentamento do estigma e as } \\
\text { dificuldades para gerir os riscos no contexto da } \\
\text { cronificação da doença. }\end{array}$} & \multicolumn{4}{|c|}{$\begin{array}{l}\text { Terceiro eixo: A dolorosa experiência de } \\
\text { submissão as violências e a possiblidade } \\
\text { da morte pelo HIV/Aids }\end{array}$} \\
\hline Classe 5 & $12,3 \%$ & Classe 3 & $14 \%$ & Classe 2 & $26,83 \%$ & Classe 4 & $11,1 \%$ & Classe 1 & $35,9 \%$ \\
\hline Palavras & Chi2 & Palavras & Chi2 & Palavras & Chi2 & irmão & 188,21 & aí & 86,62 \\
\hline homem & 148,5 & sociedade & 43,42 & pessoa & 127,46 & falecer & 105,75 & ano & 61,98 \\
\hline mulher & 116,9 & nenhum & 63,16 & alguma & 38,23 & vir & 76,96 & ficar & 51,19 \\
\hline preservativo & 64,3 & homossexualidade & 37,17 & muita & 32,4 & ciclano & 64,99 & voltar & 34,74 \\
\hline masculino & 57,62 & jeito & 36,66 & coisa & 21,12 & entender & 57,23 & professor & 28,61 \\
\hline pênis & 50,36 & gay & 36,48 & vez & 20,63 & tocar & 56,76 & lá & 27,5 \\
\hline camisa & 44,38 & casar & 53,22 & achar & 20,5 & Taguatinga & 56,06 & dar & 26,57 \\
\hline caso & 43,21 & sofrer & 33,49 & assim & 19,51 & formar & 50,62 & tempo & 19,59 \\
\hline oral & 42,37 & preferir & 30,77 & aids & 19,4 & emprego & 48,64 & depois & 17,56 \\
\hline usar & 42,37 & beijar & 30,77 & ver & 19,13 & sobrinho & 48,01 & rapaz & 17,34 \\
\hline questão & 52 & relação & 29,83 & conhecer & 18,96 & trabalhar & 47,94 & chorar & 16,48 \\
\hline normalmente & 35,89 & amigo & 29,62 & conversar & 18,52 & arrumar & 40,02 & pra & 16,08 \\
\hline natural & 35,89 & depender & 26,39 & relacionamento & 18,1 & decorrer & 35,77 & lembrar & 15,74 \\
\hline forte & 35,29 & abraçar & 24,16 & pensar & 17,4 & alugar & 33,59 & apresentar & 14,44 \\
\hline sexo & 32,5 & café & 24,26 & entender & 17,35 & público & 33,59 & passar & 14,42 \\
\hline parecer & 29,32 & mesmo & 22,33 & grupo & 14,42 & circulação & 32,35 & convidar & 12,62 \\
\hline relacionar & 29,22 & nunca & 21,41 & sujeito & 13,71 & carrinho & 32,35 & escola & 12,08 \\
\hline perfil & 28,68 & semana & 20,99 & normal & 13,71 & serviço & 32,35 & casa & 11,8 \\
\hline
\end{tabular}

Fonte: Autores.

No primeiro eixo temático, constituído pela Classe 5, evidenciou-se que todos os sujeitos estão expostos a diversos tipos de riscos. As palavras: são, elas, homens, mulheres, preservativos, masculino, pênis, camisa, caso, oral, entre outras, 
falam da exposição de "todos" a riscos de contraírem diversas Infecções Sexualmente Transmissíveis (IST), inclusive ao HIV/aids, apesar da existência dos preservativos e outros meios para proteção dessas doenças. O depoimento abaixo mostra a ocorrência de práticas sexuais inseguras, sobretudo pelos trabalhadores (as) do sexo, em que ficam submetidos à banalização do risco.

Qualquer pessoa tá sujeita a tudo: a uma Gonorréia, a uma aids, a um tipo de doença intima. Por que é isso, pega uma toalha, alguma coisa e é isso, entendeu? Que bom! De nada! - Agora você faz o resumo: tomara que dê tudo certo pra você! (Ent 2).

Evidenciou-se que o uso da camisinha é descartado quando se trata de sexo oral. Ademais, revela que na hora da negociação do ato sexual, alguns parceiros (as) não a aceitam sob o argumento que a higiene pessoal evitará as IST.

Mas a camisinha na hora que você tá fazendo o sexo oral, ela não sei. Parece que, sei lá, uma borracha não tem a mesmo contato físico como se fosse sem. E na boca você não tem cuidado, mas na hora do sexo oral, com camisinha é melhor não fazer. Quando se trata de sexo oral. Ah, com certeza. Sem preservativo. Eu tenho cuidado. Higiene é você cuidar pra você não ter doença. (Ent 1).

Os depoimentos mostram várias práticas sexuais de risco. Nesse sentido, os sujeitos destacam as tecnologias como Internet, Facebook e outras que auxiliam na promoção dos encontros para realização de práticas sexuais. Essas tecnologias facilitam, sobretudo, os encontros rápidos e com pessoas desconhecidas, que permitem certo grau de anonimato.

Aglutinar, muito! Pela internet, pelos blogs. Funciona. Acho que funciona mais pra contato sexual. Ah tá uma pessoa. No Facebook tem certos grupos fechados justamente direcionados pra sexo. E você pede a solicitação e o administrador te adiciona. E aí lá rola foto, rola pessoas é do Brasil inteiro, entendeu? É nacional. (Ent1)

Os banheiros públicos também foram reconhecidos como lugares para os encontros. Este parece ser o espaço para relações sexuais rápidas, com pessoas desconhecidas, onde se vive a emoção do risco. A esse evento costumam nominá-lo de pegação, como demonstra o depoimento abaixo:

A pessoa vai, normalmente são homens casados que vão ao banheiro pra poder fazer, digamos, pegação. Uma gíria, "pegação". Aí a gente tá lá. - Isso: vou ao banheiro, aí eu vejo que um cara ele fica mais tempo, ele fica me esperando, alguma coisa assim. Isso, ele me olha e aí ele, e a gente sim. Aí ele mostra as partes dele, aí eu vejo, e ele tá a fim de fazer pegação. (Ent 1).

O segundo eixo, compostos pelas classes três e quatro, trata do enfrentamento do estigma da homossexualidade e das dificuldades para gerir os riscos no contexto da cronificação da doença. As palavras presentes demonstram as práticas de exclusão social e da violência (sociedade, nenhum, homossexualidade, gay, revelaram os constrangimentos que sofreram no dia a dia devido à sua aparência física, principalmente quando circulavam em locais públicos), como mostra o depoimento: 
Ás vezes, a gente tá no ônibus, no metrô e a pessoa fica te olhando estranho, assim, sabe? Passa, comenta: - ah! olha a roupa dele, o jeito que ele se veste! É estranho isso, sabe? Me incomoda. Não em alto e bom tom. Às vezes tá com a outra pessoa elas comentam: ah o viadinho! Não sei o que lá (Ent 1).

Observou-se que as palavras: casar, sofrer, preferir, ilustram que as famílias, em geral, também, têm dificuldade para aceitar a pessoa que é homossexual. Geralmente não há espaço para expressar sobre a sua orientação sexual devido ao medo de sofrer represálias e rejeições.

Só que em relação a minha, não a minha, mas a homossexualidade em geral, ela é um pouco preconceituosa. Eu tive uma fase muito difícil porque eu ouvi ela dizer assim: que se tivesse um filho gay ia bater, ia expulsar de casa, essas coisas. Isso me assustou bastante. Eu não falava nem pra mim mesmo. Porque eu tinha atração por meninos. Sempre, desde criança, desde que eu me entendo por gente. E não admitia pra mim, por medo da minha mãe me rejeitar, expulsar de casa. (Ent 1).

Verificou-se, ainda, que as igrejas por meio da Bíblia têm contribuído para fomentar representações sociais negativas da homossexualidade, como sendo pessoas pecadoras e moralmente incorretas, como mostra o depoimento abaixo:

Porque você é excluído de tudo isso e aí tem muitos gays que são revoltados com Deus e reclamam das pessoas que são da igreja, mas você vê, se muita gente odeia os gays por causa da bíblia, das pessoas não precisa ser nem por causa da bíblia, mas por causa das pessoas que pregam a bíblia. Então a pessoa fica revoltada com Deus (Ent 1).

Ademais, verificou-se nos depoimentos que o preconceito e o estigma perante a homossexualidade contribuem para que a sociedade utilize corriqueiramente práticas de exclusão social.

Acho que nós gay, a gente é excluído da sociedade, excluídos muito da família, excluídos das igrejas. Eu acho assim que incomoda (Ent 4).

Diversas narrativas descreveram situações de violência sexual a que foram submetidas, na infância ou na adolescência, extremamente agressivas, que causaram traumas físicos e emocionais relevantes.

Eu sofri; então eu sofri esse abuso; ele era um adulto, porque um rapaz de 17 anos e uma criança de 6 anos; então eu sofri esse abuso. Naquilo ali foi àquela farra, ele tirou sangue em mim na época (Ent 3).

Em salvador teve um episódio traumático que eu pulei. Aí, não sei por quê. Voltando agora, mas um garoto me pegou na escada à força. Não, quando eu era adolescente, com doze anos. E me sangrou, entendeu, assim, mas assim, mais ou menos isso. Mas eu consegui sair rápido, mas assim mesmo ele rasgou minha roupa e eu fiquei sangrando e depois eu morria de medo porque ele continuava morando no quarto andar e eu no sétimo, sabe assim (Ent 6).

Ainda no segundo eixo temático, na Classe 2, as palavras: pessoas, alguma, muita, coisa, vez, achar, assim, aids, evidenciam as dificuldades para gerir o risco em razão da cronificação da doença, possivelmente porque as pessoas perderam o medo de contrair a doença, como revela o depoimento: 
Acho que as pessoas têm mais medo de câncer do que de aids. Eu vejo também no câncer, eu acho que é pior do que a aids. Do que uma aids. Porque o câncer ele come a pessoa por dentro. É, eu acho. Não só sobre a aids (Ent 7).

Observou-se que a banalização da doença, devido à sua cronificação contribui para o aumento do risco de contrair o HIV/aids. Revelam, também, que as mídias têm colaborado para a formação desse tipo de representação social, ou seja, de que a aids não mata mais, pois pode ser tratada.

Pra tratamento de aids. Então acho que isso as pessoas não fala tanto nas mídias. Então fica uma coisa meio que: "ah se eu tiver aids, eu posso ser tratado que eu vou normalmente". Acho que muita gente pensa assim. Muita gente (Ent 1).

Foi observado que outra dificuldade se refere à projeção do risco de contrair a doença para o outro, como consequência relaxam nos cuidados que possuem consigo mesmo. Verificou-se que o afeto constitui outro fator que contribui para o não reconhecimento do risco em decorrência da confiança depositada no outro.

O último eixo temático é constituído pelas classes 4 e 1, e revelou a experiência de conviver com o sofrimento e morte da pessoa que adquiriu HIV/aids. A classe 4 destaca as palavras: falecer, vir, ciclano, entender, entre outras, que mostram que a doença ainda mata.

E muito pouca chance, que esse povo tem? Morrem muito rápido. Você não tem o que oferecer (Ent4).

$\mathrm{Na}$ classe dois, as palavras: ano, ficar, voltar, evidencia a experiência de conviver com o sofrimento de a pessoa adquirir HIV/aids. Em realidade, mostra um longo processo de coexistência com a doença, experiência com o serviço de saúde, com o acompanhamento e tratamento, conforme ilustra o depoimento abaixo:

No centro, geralmente eles são os médicos são mais sensíveis. Aí depois eles mandam você ir pro hospital tirar raio x, alguma coisa assim. Aí até chegar a consulta é meses, digamos assim. É muito tempo. Na época eu tinha uns dezesseis anos. Uns três anos. Eu fui agora no endocrinologista. Ele pediu um exame de sangue, mas só. Antigamente tinha umas carretas assim que o governo colocou. Pra teste de aids, alguma coisa assim, não me falaram. Não. Não. Não, não fala. Eu acho que da minha geração a gente não viu o que vocês viram quando estourou essa coisa de aids. Então, o Brasil é um país de referência. Pra tratamento de aids. Então acho que isso as pessoas não fala tanto nas mídias. Então fica uma coisa meio que: - ah se eu tiver aids, eu posso ser tratado que eu vou normalmente. Acho que muita gente pensa assim. Muita gente.

$\mathrm{Na}$ analise de Similitude (figura 2), podemos identificar nos grafos, que, de um lado, as palavras: aí, gente, ficar, pra, falar, entender, minha, e as demais ilustram o árduo processo de negociação da prática sexual com proteção. Do outro lado, as palavras destacadas são: assim, dizer, pessoa, coisa, achar, e outras estão associados às dificuldades para proteger-se do risco, pois se trata de uma relação que envolve a "pessoa" que não sou eu, portanto é o outro que irá julgar se irá usar "coisa", palavra comumente usada para se referir ao preservativo. 
Figura 2 - Analise de Similitude das Representações Sociais do HIV-aids e gestão de risco em tempos de cronificação da doença

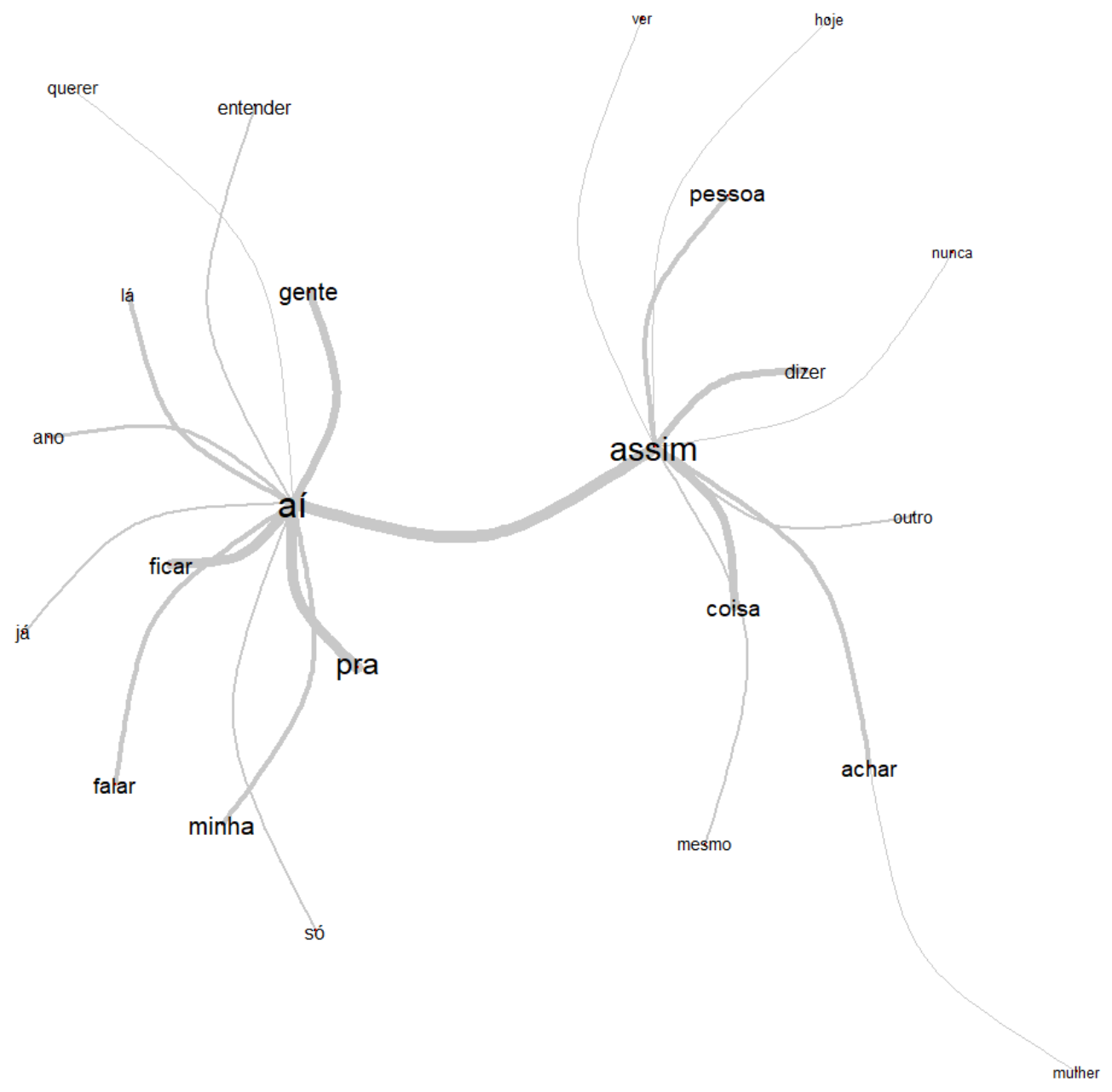

Fonte: Autores.

\section{Discussão}

As representações do HIV/Aids são de uma doença estigmatizante que ainda causa a morte, e continua gerando exclusões sociais e violências. As histórias de vida revelaram que o HIV/aids ainda é causador de forte discriminação, que se trata de uma espécie de resposta comportamental ao estigma e ao preconceito, definidos como atitudes negativas em relação ao valor de grupos sociais específicos (Parker \& Aggleton, 2003; Massignam et al.,2015).

Verificou-se que prevalece uma forte associação entre HIV/aids e a homossexualidade, sendo esta orientação sexual ainda muito estigmatizada socialmente, inclusive pelos seus familiares, que os reprimem e os excluem. Em geral as famílias comportam-se influenciados por uma gama de significados estigmatizantes que envolvem a doença e que foram construídos socialmente, podendo interferir nas relações dentro e fora do grupo familiar (Hoyos-Hernández et al., 2019). Segundo os mesmos autores, a falta de informações sobre a doença no que tange à etiologia, formas de transmissão, tratamento, implicações psicossociais podem ter corroborado para a criação dessas representações sociais negativas da doença e sua relação com a homossexualidade (Barbará et al., 2005). 
Entretanto, constataram-se neste e em outros estudos que "todos os que têm vida sexual estão sujeitos"; e há certo grau de imponderabilidade do risco, no sentido de que ninguém pode dizer que está completamente livre de contrair o HIV/aids" (Simões et al., 2010, 2018).

Todavia, observou-se que existe grande dificuldade de todas as pessoas, independente do gênero, para se realizar a gestão do risco de contrair HIV/aids, que certamente estão relacionadas ao novo momento da doença, o da cronificação, que tem sido denominado de "nova aids", possibilitados pelos avanços nas tecnologias de tratamento, prevenção e, junto com sua difusão, permitiram recolocar em outros termos a associação entre HIV/aids e morte (Agostini et al., 2017; Simões, 2018; Cunha, 2018; Abreu et al., 2020). Além disso, o modelo predominantemente biomédico de política de cuidado tem se constituído uma importante barreira organizacional (Teixeira et al., 2018), sobretudo porque não possibilita a construção do saber baseado na experiência dos sujeitos, centrados nas motivações, na apropriação de habilidades de cuidados com vistas a aplicá-los para si mesmo e passar para os outros (Jodelet, 2014).

As novas tecnologias de comunicação possibilitaram e estimularam os encontros para atividades sexuais com mais rapidez e facilidade, dificultando ainda mais a gestão para prevenir o risco de contrair o HIV/aids (Simões, 2018). Nesse sentido, neste estudo observaram-se relatos de práticas bastante flexíveis em relação ao uso da camisinha como estratégia de prevenção (Silva \& Iriart, 2010; Simões, 2018). Esses problemas não são novos, são persistentes, apesar das campanhas de prevenção das Infecções Sexualmente Transmissíveis.

Ademais, revelou-se neste estudo que a negociação da prática de prevenção é bastante dificultada porque envolve o outro na tomada decisão, num contexto, muitas vezes, de prática sexual rápida e imediata, em que prevalece a negação do risco de contrair o HIV/aids. Geralmente essa negação está relacionada a um subterfúgio de proteção, no qual ocorre a falsa percepção de que o "meu grupo" ou "a gente" está protegido (Leal \& Coêlho, 2016). Trata-se, pois de estratégia projetiva, em face da ameaça. Em realidade, é uma das formas primarias, pela qual as pessoas se defendem de medos associados à HIV/aids, projetando a responsabilidade do risco de contrair a doença em outros, distanciando-se, desse modo, da situação ameaçadora (Leal \& Coêlho, 2016; Rios et al., 2019).

O uso da camisinha é objetivado como o principal recurso para prevenção da IST, contudo, o abandono circunstancial do uso delas ocorre, comumente, nas relações percebidas como afetivas e intensas, gerando dificuldades nas conversas ou negociações verbais (Simões, 2018). Ademais, em algumas situações, o afeto contribui para modular negativamente o controle do risco, chamando a atenção para a necessidade de repensar e retomar estratégias de prevenção em termos de "gestão de risco" e "segurança negociada".

Destacou-se, também, que os profissionais do sexo ainda encontram dificuldades para negociar o uso da camisinha, sobretudo quando os clientes não o querem, expondo-os ao risco de contraírem diversos tipos de IST. Vários fatores contribuem para fragilizar essas pessoas no processo de negociação da prática sexual segura, como a baixa autoestima, estigmatização, a exclusão social e, especialmente, a necessidade do dinheiro para sua sobrevivência (Couto et al., 2020; Abreu et al., 2020).

Nesse sentido, embora a prevenção contra HIV/aids componha as representações sociais dos sujeitos envolvidos neste estudo, na prática, encontra dificuldade para ser operacionalizada. Outra questão que corrobora para o relaxamento das medidas de prevenção é a representação de que as simples medidas de higiene podem impedir a aquisição da doença, que se trata do uso da negação que impede a ancoragem no saber científico, (Cardoso \& Arruda, 2004), indicando a necessidade de reforço constante das orientações dialógicas corretas acerca das medidas preventivas.

Ademais, atualmente existe espécie de "cardápio preventivo" em expansão (Zucchi et al., 2018), com o desenvolvimento e a oferta pública de novas técnicas, como a profilaxia pós-exposição (PEP), novas modalidades de teste 
rápido e a profilaxia pré-exposição (PrEP), que se de um lado ajuda na prevenção, de outro torna as escolhas mais complexas (Ferraz \& Paiva, 2015; Grangeiro et al., 2018).

É relevante destacar que, mesmo quando implementadas pela ótica do autocuidado, as formas de gestão de si articuladas à imagem da "nova aids", como enfermidade tratável ou manejável continuam a deixar para a pessoa solitária a responsabilidade pela gestão de riscos (Simões, 2018, Calazans, 2018). Seus efeitos em termos de uma modalidade renovada de "gestão do silêncio" constituem um desafio aos esforços de promoção de solidariedade social para com as pessoas que convivem com HIV/aids, bem como constituem-se barreira persistente à aceitação social das diversas expressões da sexualidade, revelando uma clara vulnerabilidade programática pública (Calazans, 2018).

A despeito das limitações do estudo, que não abrangeu todos os segmentos expostos ao HIV/aids, permitiu evidenciar aspectos importantes, especialmente que a tendência de cronificação da doença favorece a negação do risco, e exige novas estratégias de abordagem de prevenção. Assim sendo, enquanto o vírus estiver circulando, ainda há que se enfrentar o desafio da educação e do aconselhamento sobre a sexualidade humana, respeitando os termos e valores das pessoas, a identidade sexual e seus desejos, que é o modo mais eficiente de educar sobre todos os métodos preventivos (Ferraz \& Paiva, 2015).

As campanhas de prevenção as IST não tem sido satisfatórias, sobretudo entre os jovens (Hoyos-Hernández et al., 2019), que preferem outras fontes de informações mais fáceis e ágeis, como a internet e outras mídias sociais. Para tanto, são necessárias ações de educação em saúde com metodologias que desconstruam crenças, valores e atitudes negativas sobre a doença, e proporcionem interações que promovam comportamentos positivos em relação as praticas sexuais saudáveis e seguras.

A negação e a exclusão dos sujeitos mais vulneráveis, possivelmente podem corroborar para a piora desse cenário (Flores \&Yolanda, 2016; Teixeira et al., 2018). Dessa forma, é imprescindível um bom nível de informação sobre HIV/aids, o que implica enfrentar preconceitos e discriminações persistentes sobre sexo e sexualidade, de forma que o acesso aos serviços de prevenção de IST se realize de maneira acolhedora.

\section{Considerações Finais}

As representações do HIV/aids são de uma doença estigmatizante, que continua gerando exclusões sociais e violências. A gestão do risco no contexto da cronificação da doença tem sido complexa e multifacetada, apesar do aumento de ferramentas que podem ser usadas para tratamento e prevenção nos últimos anos. A negação da possibilidade de contrair a doença continua contribuindo fortemente para adoções de praticas sexuais arriscadas, sem proteção. Desta forma, enquanto o vírus estiver circulando, há que se continuar investindo na educação sobre todos os métodos preventivos, que inclua o aconselhamento sobre sexualidade, respeitando os termos e valores das pessoas, a identidade sexual e seus desejos. São necessárias estratégias inovadoras, que reforcem a importância do autocuidado da sexualidade responsável, integradas e interrelacionadas às diferentes etapas do curso da vida.

Consideram-se como limitações do estudo, a restrição do número de participantes de cada segmento e circunscritos ao Distrito Federal, bem como a não abrangência todos os segmentos expostos ao HIV/aids, além de não aprofundar a questão da profilaxia pré-exposição (PrEP), que poderá ser realizados em outros estudos, pois envolve uma nova faceta dos cuidados com a doença.

\section{Agradecimentos}

Agradecemos Ximena Pamela Diaz-Bermudez e Edgar Merchan-Hamann pela oportunidade de participação neste recorte da pesquisa. Agradecemos também aos estudantes que estiverem envolvidos na realização das entrevistas. 


\section{Referências}

Abreu, P. D., Araújo, C. E., Vasconcelos, C. M. R., Ramos, V. P., Moura, J. W. S. \& Santos, Z. C, et al.(2020). Social representations of transsexual women living with HIV/AIDS. Rev. Bras. Enferm, 73, (3), e20180390.

Agostini, R, Maksud, I \& Franco, T. (2017). Essa doença para mim é a mesma coisa que nada: reflexões socioantropológicas sobre o descobrir-se soropositivo. Saude soc., 26, (2), 496-509.

Barbará, A, Sachetti, V.A. R \& Crepaldi M. A.(2005). Contribuições das Representações Sociais ao estudo da AIDS. Interação em Psicologia, 2005, 9(2), p. 331-339.

Calazans, G. J. (2018). Vulnerabilidade programática e cuidado público: Panorama das políticas de prevenção do HIV e da Aids voltadas para gays e outros HSH no Brasil. Sexualidad, Salud y Sociedad, 29, 263-293.

Camargo, B. V., \& Justo, A. M. (2013). IRAMUTEQ: Um software gratuito para análise de dados textuais. Temas em Psicologia, 21 (2), $513-518$.

Camargo, B. V., \& Justo, A. M. (2015). Tutorial para uso do software IRAMUTEQ. http://www.laccos.com.br/index.php?option=com_content\&view=article \&id=208\%3Atutorial-do-software-iramuteq-em-portugues\&catid=40\%3Aoutros\&Itemid=9\&lang=br.

Cardoso, G. P. \& Arruda, A. (2004). As representações sociais da soropositividade e sua relação com a observância terapêutica. Ciênc. saúde coletiva, 10, (1), $151-162$.

Cecilio, H. P. M., Oliveira, D. S., Apostolidis, T., Dany, L., \& Oliveira, D. C. de. (2020). Time perspective, socioeconomical status and quality of life of people living with HIV. Research, Society and Development, 9(8), e148985451.

Couto, P. L. S., Porcino, C., Pereira, S. S. da C., Neri, F. G., Azevedo, C. N., Vilela, A. B. A., Gomes, A. M. T., \& Flores, T. da S. (2020). “Money as a synonym for pleasure?" procedural analysis of the representational meanings of sex workers on sexual satisfaction. Research, Society and Development, $9(8)$, e854986233.

Cunha, C.C. (2018). Configurações e reconfigurações do movimento de jovens vivendo com Hiv/Aids no Brasil: Identidades e prevenções em jogo. Sex, Salud y Soc, 29, 294-312.

Ferraz, D. \& Paiva, V. (2015). Sexo, direitos humanos e AIDS: uma análise das novas tecnologias de prevenção do HIV no contexto brasileiro. Rev. bras. epidemiol. 18 (Suppl 1), 89-103.

Flores, Y., Yolanda R. (2016). Sexual violence as a limiting factor on the perception and management of the risk of HIV in women married to migrants. Rev. Latino-Am. Enfermagem, 2016, 24.

França, L. C. M., Gomes, A. M. T., Nogueira, V. P. F., Mercês, M. C. das, \& Couto, P. L. S. (2020). Spirituality for people living with HIV/AIDS: an analysis of the procedural approach of social representations. Research, Society and Development, 9(8), e443985903.

Hipólito, R. L., Oliveira, D. C. de, Cecilio, H. P. M., Marques, S. C., Flores, P. V. P., Costa, T. L. da, \& Lima, F. O. de. (2020). Quality of life of people living with HIV and their multifactorial relationships. Research, Society and Development, 9(7), e82973749.

Hoyos-Hernández, P.A., Mazo, J.P.S, Pineda, L.T.O., Gallego, A. L.V., Ceballos, M.G. Muñoz T.O. et al. (2019). Representaciones sociales asociadas al VIH/Sida en universitarios colombianos. Saude soc., 28 (2), 227-238.

Jodelet, D. (2001). Representações sociais: um domínio em ex-pansão. Em D. Jodelet (Org.), As representações Sociais (pp. 17-29). Eduerj.

Jodelet D. (2014). A propos des jeux et enjeux de savoir dans l'Education Thérapeutique des Patients. https://www.academia.edu/37785446/A propos_des_jeux_et_enjeux_de_savoir_dans_lEducation_Th\%C3\%A9rapeutique_des_Patients

Kerr, L. R., Mota, R. S., Kendall C., Pinho A. A, Mello M. B., Guimarães M. D., Dourado, I. et al. (2013). HIV among MSM in a large middle-income country. AIDS, 27(3), 427-35.

Kerr L, Kendall C, Guimarães M. D. C., Mota, R. S, Veras, M. A, Dourado, I., Brito, A. M. et al. (2018). HIV prevalence among men who have sex with men in Brazil: results of the 2nd national survey using respondent-driven sampling. Medicine, 97(1S Suppl 1), S9-S15.

Leal, N. S. B., Coêlho, A. E. L. (2016). Representações sociais da AIDS para estudantes de Psicologia. Fractal: Revista de Psicologia, 28(1), 9-16.

Massignam, F, M. Bastos, J. L. D. \& Nedel, F. B. (2015). Discriminação e saúde: um problema de acesso. Epidemiol. Serv. Saúde 24 (3), 541-44.

Ministério da Saúde (BR). (2020). Secretaria de Vigilância em Saúde. Departamento de DST, Aids e Hepatites Virais. HIV/AIDS. Bol Epidemiológico. http://www.aids.gov.br/pt-br/pub/2020/boletim-epidemiologico-hivaids-2020.

Parker, R. \& Aggleton, P. (2003). HIV and Aids-related stigma and discrimination: a conceptual framework and implications for action. Social Science \& Medicine, 57(1), 13-24

Pereira, G. F.M, Shimizu, H. E., Bermudez, X. P. \& Merchan-Hamann, E. (2018). Epidemiologia do HIV e aids no estado do Rio Grande do Sul, $1980-2015$. Epidemiol. Serv. Saúde, 27 (4), 1-11.

Rios, L. F., Albuquerque, A. P., Santana, W., Pereira, A. F., Oliveira Junior, C. J. (2019). O drama do sexo desprotegido: estilizações corporais e emoções na gestão de risco para HIV entre homens que fazem sexo com homens. Sex., Salud y Soc.,32, 65-89.

Silva, A. M. B. da \& Enumo, S. R. F. (2017). Descrição e Análise de uma Intervenção Psicológica com Bailarinos pelo Software IRAMUTEQ. Temas em Psicologia, 25 (2), 577-593. 
Research, Society and Development, v. 10, n. 10, e257101018357, 2021

(CC BY 4.0) | ISSN 2525-3409 | DOI: http://dx.doi.org/10.33448/rsd-v10i10.18357

Silva, L. A. V \& Iriart, J. A. B. (2010). Práticas e sentidos do barebacking entre homens que vivem com HIV e fazem sexo com homens. Interface, 14, (35), 739-52. Simões, J.A. (2018). Gerações, mudanças e continuidades na experiência social da homossexualidade masculina e da epidemia de Hiv-Aids. Sex, Salud y Soc, 29,313-339.

United Nations. (2016) Global report: UNAIDS report on the global AIDS epidemic: Geneve: United Nations.

World Health Organization. (2000). United Nations Programme on HIV/AIDS. Guidelines for second-generation HIV surveillance. UNAIDS/World Health Organization. 40 p. http://www.who.int/hiv/pub/surveillance/en/cds_edc_2000_5.pdf.

Teixeira, F. B., Paulino, D. B., Raimond, G. A., Crovato, C. A. S., Prado, M. A. M. (2018). Entre o segredo e as possibilidades do cuidado: (re) pensando os silêncios em torno das narrativas das travestis sobre HIV/AIDS. Sex., Salud Soc. 2018, 29: 373-388.

Grangeiro, A., Ferraz, D, Pinheiro, T. F., Alencar, T. Ferguson, L, Estevam, D. L., Munhoz, R. (2018). Da evidência à ação: desafios do Sistema Único de Saúde para ofertar a profilaxia pré-exposição sexual (PrEP) ao HIV às pessoas em maior vulnerabilidade. Cadernos de Saúde Pública, 34(7), e00206617. 